\title{
Investigation of Velocity Influence on Cathodic Polarization of Aluminum Alloys in 3.5\% NaCl by Electrochemical Impedance Spectroscopy
}

\author{
Karim Akbari Vakilabadi ${ }^{1 *}$, Hossein Khanzadi ${ }^{2}$ \\ 1 Assistant Professor, Marine Faculty of Imam Khomeini Maritime Academy, Nowshahr, Iran; \\ Akbari.karim@gmail.com \\ ${ }^{2}$ Assistant Professor, Department of Navigation Faculty of Imam Khomeini Maritime Academy Iran, \\ Nowshahr; hk.patriot6@gmail.com
}

\section{ARTICLE INFO}

\section{Article History:}

Received: 6 Mar. 2019

Accepted: 30 Jul. 2019

\section{Keywords:}

Pitting Corrosion

Aluminum Alloys

EIS

Mansfeld's Model

\begin{abstract}
Aluminum-magnesium alloys are specially used in high speed boats, submarines, desalination systems, etc. In this re-search the electrochemical impedance spectroscopy technique was utilized to study the flow accele-rated pitting corrosion behavior of this alloy in $3.5 \% \mathrm{NaCl}$ solution. To do so, impedance spectra of the samples after $20 \mathrm{~h}$ of exposure to the test solution at a rotation speeds were investigated. SEM (scanning electron microscopy) method was utilized to investigate the changes in the surface of the samples. Results indicated that under static and dynamic con-dition, the surface growth rate of the pits increases with time. Moreover, at $-0.9 \mathrm{~V}$ upon altering the flow condition from static to dynamic, the surface growth rate of the pits and their surface fraction increases while the corrosion resistance of the passive layer is time dependent.
\end{abstract}

\section{Introduction}

Due to their excellent corrosion resistance to sea water, aluminum-magnesium alloys are widely used in naval applications where they are exposed to severe hydrodynamic conditions [7, 12, and 14]. Regardless of the presence of chloride, heterogeneities either it the metal itself, the medium or in the exposure conditions, generally lead to the common phenomenon of pitting corrosion of aluminum-magnesium alloys [8, 15]. This type of local corrosion often occurs in forms of crevices around the noble, iron-containing intermetallic particles as a result of micro galvanic coupling between them and the active surrounding solid solution aluminum matrix [1].

Several studies proposed that increasing the flow rates of seawater mitigates the possibility of pitting corrosion that is mostly occurred in stagnant and low flow rate environments whilst in-creasing the rate of uniform corrosion $[5,6]$.

Some researchers believe that pitting corrosion occurs on intermetallic particles because of the disruption and removal of the oxide layer formed on them under flowing conditions and that the localized flow conditions on these pits and hydrodynamic shear stresses shear the particles off and remove the galvanic cell, leading to a decrease in the pitting corrosion rate. They also believe that the form and rate of corrosion of aluminum under hydrodynamic conditions depend on flow velocity $[2,4]$.

Since electrochemical impedance spectroscopy (EIS) technique provides information on different processes that take place simultaneously in any complex system, it has been extensively used to study the corrosion processes $[3,9]$. Current research aims to investigate the pitting corrosion mechanism of AA5083-H321 aluminum-magnesium alloy in $\mathrm{NaCl}$ solution under hydrodynamic conditions by means of (EIS) technique. This technique enables us to distinguish the roles of electrochemical and mechanical factors in the pitting corrosion mechanism.

\section{Experimental}

In this study, cylindrical wrought aluminummagnesium alloy samples having the dimensions of 20 $\mathrm{mm}$ diameter and $15 \mathrm{~mm}$ height and chemical composition as given in Table 1, were used. A rotating cylinder electrode (RCE) system was utilized to simulate the hydrodynamic conditions.

Table 1. Composition of samples (wt.\%)

\begin{tabular}{llllll}
\hline $\mathrm{Mg}$ & $\mathrm{Cr}$ & $\mathrm{Ti}$ & $\mathrm{Sn}$ & $\mathrm{Pb}$ & $\mathrm{Zn}$ \\
4.6 & 0.087 & 0.045 & 0.06 & 0.0057 & 0.05 \\
\hline $\mathrm{Ni}$ & $\mathrm{Mn}$ & $\mathrm{Fe}$ & $\mathrm{Cu}$ & $\mathrm{Si}$ & $\mathrm{Al}$ \\
0.0002 & 0.8 & 0.7 & 0.28 & 0.2 & Rest \\
\hline
\end{tabular}


To exclusively expose the required surface of the samples to the electrolyte, their top and bottom faces (circular faces) were painted off with two layers of epoxy.

Samples were abraded with SiC paper down to 1500 grit, polished with alumina paste to $6 \mathrm{~lm}$, degreased with acetone and rinsed by distilled water. $\mathrm{NaCl}$ solution of $\mathrm{pH}=7$ was used as test solution and tests were conducted at room temperature. Nitrogen gas was injected to de aerate the tests solutions 30 minutes before each test.

EIS tests were conducted using a Potentiostat/ Galvanostat (EG\&G Princeton Applied Research 273A) coupled to a model 1025 frequency response analyzer. The amplitude of the applied AC signal was $\pm 10 \mathrm{mV}$, and the frequency ranged between $0.01 \mathrm{~Hz}$ and $100 \mathrm{KHz}$. The equivalent cir-cuits simulating the electrochemical response of the system were constructed making use of Zview2 software.

\section{Results}

\subsection{SEM analysis}

Figure 1 shows SEM images of SCE and RCE samples polarized after 20 hours at $-0.9 \mathrm{~V}$ SCE. Black and white spots seen in the figures indicate the pits and secondary phases respectively. Some white regions are marked in the figures which seem to be Iron containing particles. During Aluminum production, the residual Iron will remain in the matrix. Since Iron solubility in $\mathrm{Al}$ is low, it will precipitate in Al matrix forming inter-metallic phases. Some white regions are marked in the figures which seem to be Iron containing particles. During Aluminum production, the residual Iron will remain in the matrix. Since Iron solubility in $\mathrm{Al}$ is low, it will precipitate in $\mathrm{Al}$ matrix forming inter-metallic phases.

\subsection{Electrochemical Impedance Spectroscopy}

In this experiments 5083 Al-alloy samples were polarized for 20 hours at $-0.9 \mathrm{~V}$ potential and the impedance data was obtained $0,2.5,5,10,15$, and 20 hours after the polarization started.

Figure 2 shows the Bode phase diagrams obtained from Electrochemical Impedance Spectroscopy tests which were carried out on SCE and RCE samples polarized at $-0.9 \mathrm{~V}$ for $0,2.5,5,10,15$, and 20 hours after the experiment started. In $\log f-\log \mathrm{z}$ diagram, two maximums can be seen in phase angle, the second one being located in low frequencies $(0.01-0.1 \mathrm{~Hz})$ i.e. two time constants can be observed in these plots. (a)

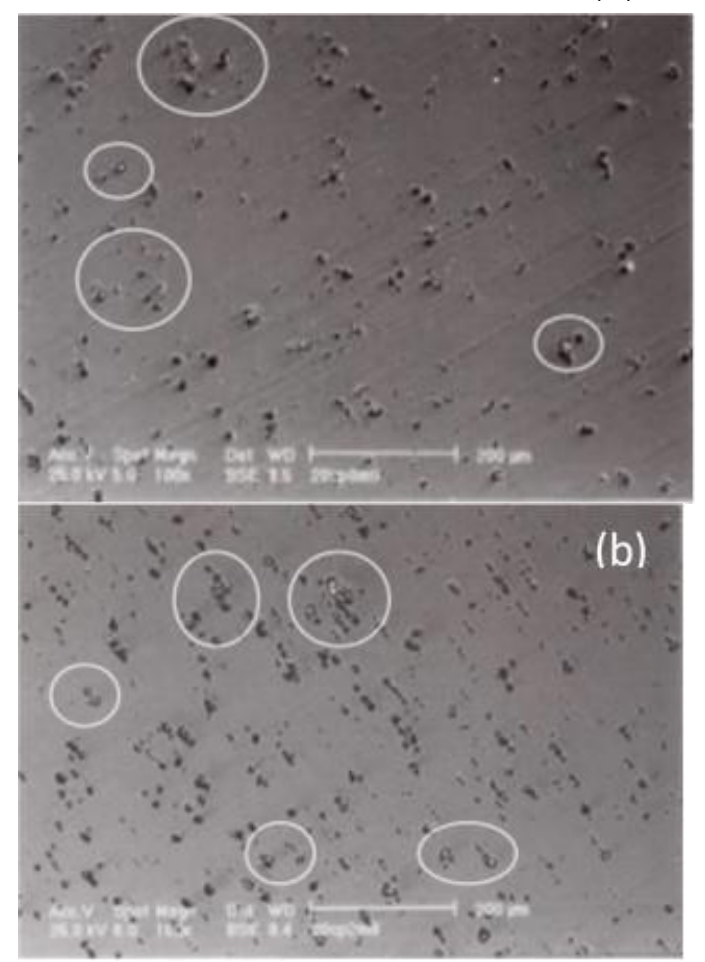

Figure 1. SEM images of AL5083 samples polarized in -0.9V for 20 hours in NaCl solution, a) SCE, b) RCE

Table 2. Pitted surface fraction of Al5083 alloy samples after 20 hours of cathodic polarization at $\mathbf{- 0 . 9} \mathrm{V}$ in $\mathrm{NaCl}$ solution.

\begin{tabular}{ccc}
\hline Parameter & RCE & SCE \\
\hline F & 3.2 & 2.8 \\
\hline
\end{tabular}

Basically, general form of the plots for different samples do not change i.e. there is no change in the correlation between impedance and frequency, but the numerical value of impedance may change in different times. These changes will be discussed further in data analysis using equivalent circuit.

Mansfeld Physical model was utilized for analysis of diagrams [9]. In this equivalent circuit, solution resistance denotes the uncompensated resistance between the reference electrode and the working electrode. $R_{p}$ and $C_{p}$ are polarization resistance and capacitance of the passive surface respectively. $R_{\text {pit }}$ and $\mathrm{C}_{\mathrm{pit}}$ are the same parameters for regions where local corrosion occurs. F is the pitted surface fraction on the samples. $R_{\text {pit }} / F$ is the pits growth rate on the surface. $W$ describes the transmission behavior and diffusion processes in low frequencies and local corrosion occurrence is evident by its presence. Figure 4 shows Mansfeld's equivalent circuit and equivalent physical structure. 


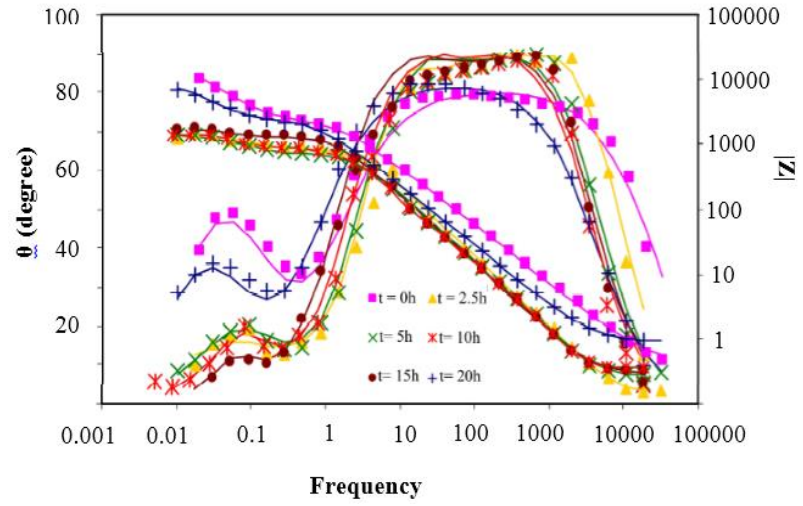

(a)

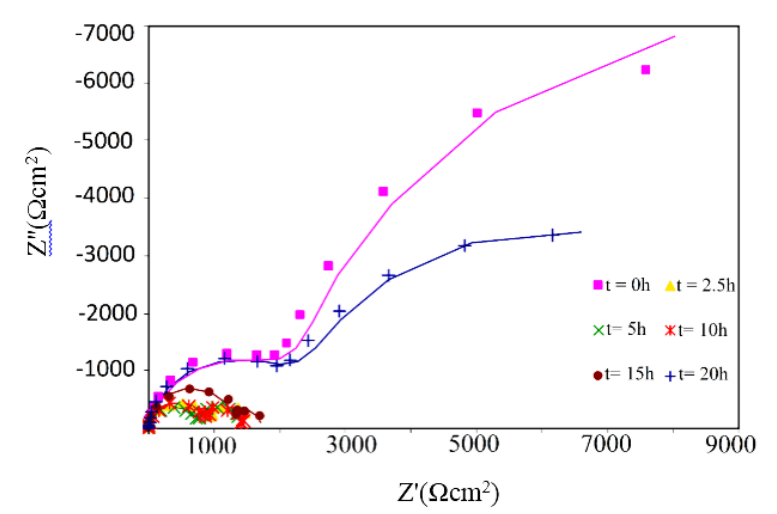

(b)

Figure 2. a) Bode, and b) Nyquist plots of experimental and simulated data of SCE Al5083 sample polarized for different durations at $\mathbf{- 0 . 9 \mathrm { V }}$ (SCE ref.) in $\mathrm{NaCl}$ solution.

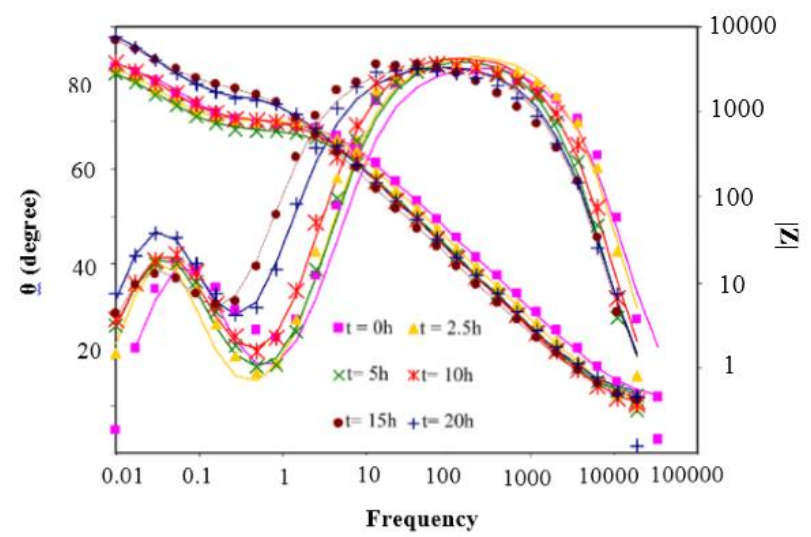

(a)

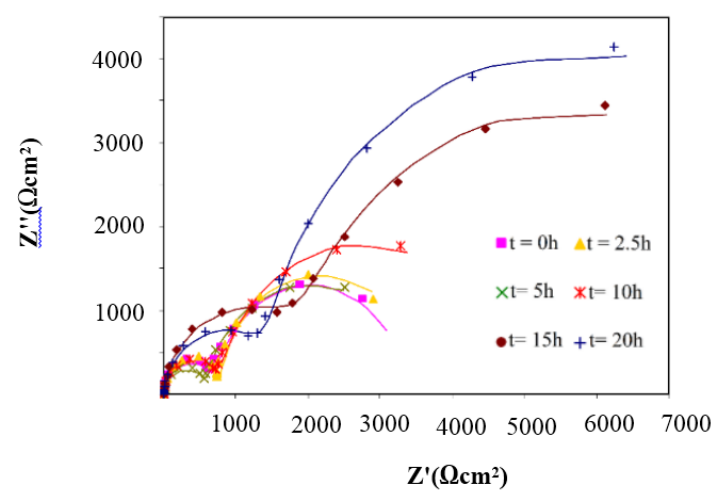

(b)

Figure 3. a) Bode, and b) Nyquist plots of experimental and simulated data of RCE Al5083 sample polarized for different durations at $-0.9 \mathrm{~V}$ (SCE ref.) in $\mathrm{NaCl}$ solution.



Figure 4. Mansfeld's model for impedance data analysis of Aluminium pitting process.

The equivalent circuit proposed by Zview software to analyze the localized corrosion impedance data is a modified version of Mansfeld model (Figure 5). $\mathrm{FC}_{\mathrm{pit}}$ and $\mathrm{C}_{\mathrm{p}}(1-\mathrm{F})$ are parallel and hence not recognizable from one another, therefore, in the model proposed by this software, $\mathrm{Ct}$ is utilized. The total capacitor used in the model as a constant phase element to compensate the inhomogeneity of the system includes the metal surface. $R_{\text {pit1 }}$ and $R_{\text {pit2 }}$ represent $R_{p} /(1-F)$ and $R p i t / F$ respectively.

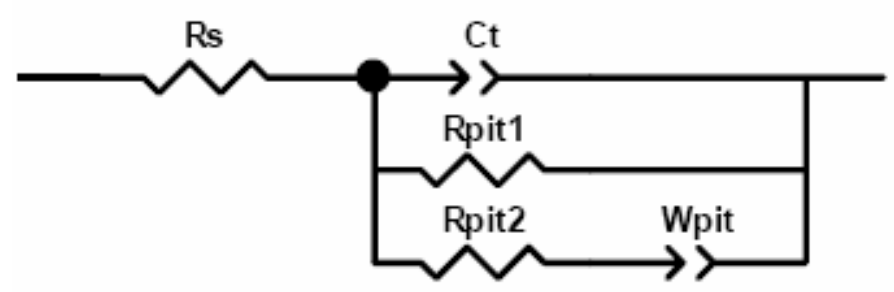

Figure 5. Equivalent circuit proposed by Zview software to analyze the impedance data obtained for pitting

The numeral values of the equivalent circuit elements were calculated using the model shown in figure 4 and computer software and the results are given in Table 3 .

Table 3. EIS results of SCE Al5083 samples polarized for different times at $\mathbf{- 0 . 9} \mathrm{V}$ in $\mathrm{NaCl}$ solution

\begin{tabular}{ccccccc}
\hline $\begin{array}{c}\text { Time } \\
(\mathrm{hr})\end{array}$ & $\begin{array}{c}\mathrm{C}_{\mathrm{t}} \mathrm{T} \\
(\mu \mathrm{F})\end{array}$ & $\mathrm{Ct}-\mathrm{P}$ & $\begin{array}{c}\mathrm{R}_{\text {pit1 }} \\
(\Omega)\end{array}$ & $\begin{array}{c}\mathrm{R}_{\text {pit2 }} \\
(\Omega)\end{array}$ & $\begin{array}{c}\mathrm{W}_{\text {pit }} \mathrm{T} \\
\left(\Omega^{-1}(\mathrm{rad} / \mathrm{s})^{\mathrm{n}}\right)\end{array}$ & $\mathrm{W}_{\text {pit }} \mathrm{P}$ \\
\hline 0 & 52.614 & 0.9007 & 18170 & 3142 & 0.003947 & 0.9253 \\
\hline 2.5 & 50.999 & 0.9968 & 1823 & 1384 & 0.0010171 & 0.70246 \\
\hline 5 & 76.334 & 0.9987 & 1467 & 1376 & 0.0010932 & 0.89726 \\
\hline 10 & 56.443 & 0.9877 & 1420 & 2148 & 0.000822 & 0.999 \\
\hline 15 & 81.993 & 0.9982 & 1686 & 6153 & 0.00043834 & 0.9876 \\
\hline 20 & 91.539 & 0.92635 & 10176 & 3487 & 0.00074814 & 0.90001 \\
\hline
\end{tabular}


Table 4. EIS results of RCE Al5083 samples polarized for different times at $\mathbf{- 0 . 9} \mathrm{V}$ in $\mathrm{NaCl}$ solution

\begin{tabular}{ccccccc}
\hline $\begin{array}{c}\text { Time } \\
(\mathrm{hr})\end{array}$ & $\begin{array}{c}\mathrm{C}_{\mathrm{t}} \mathrm{T} \\
(\mu \mathrm{F})\end{array}$ & $\mathrm{Ct}-\mathrm{P}$ & $\begin{array}{c}\mathrm{R}_{\text {pit1 }} \\
(\Omega)\end{array}$ & $\begin{array}{c}\mathrm{R}_{\text {pit2 }} \\
(\Omega)\end{array}$ & $\begin{array}{c}\mathrm{W}_{\text {pit-T }} \\
\left(\Omega^{-1}(\mathrm{rad} / \mathrm{s})^{\mathrm{n}}\right)\end{array}$ & $\mathrm{W}_{\text {pit-P }}$ \\
\hline 0 & 60.948 & 0.93158 & 3327 & 1036 & 0.0011361 & 0.9925 \\
\hline 2.5 & 67.105 & 0.95282 & 3567 & 1083 & 0.0020092 & 0.9965 \\
\hline 5 & 85.489 & 0.95132 & 3497 & 762.1 & 0.0021312 & 0.93082 \\
\hline 10 & 89.502 & 0.95159 & 4763 & 1015 & 0.0015257 & 0.92707 \\
\hline 15 & 130.32 & 0.92177 & 9420 & 2956 & 0.00081211 & 0.92115 \\
\hline 20 & 106.18 & 0.92489 & 10108 & 1983 & 0.00091666 & 0.95953 \\
\hline
\end{tabular}

Figure 6 shows $\mathrm{C}_{\mathrm{t}}$ diagrams as a function of time for RCE and SCE samples at $-0.9 \mathrm{~V} \mathrm{SCE}$. $\mathrm{C}_{\mathrm{t}}$ is an indicator of pits nucleation and as Mansfeld's studies have shown, its increases upon nucleation of pits on the surface, due to increase in ECt share. In other word, if $\mathrm{C}_{\mathrm{p}}$ (capacitive element of the passive surface) is fixed, $\mathrm{C}_{\mathrm{t}}$ variation is an indicator of $\mathrm{FC}_{\mathrm{pit}}$ variation and hence variation in nucleation of pits.

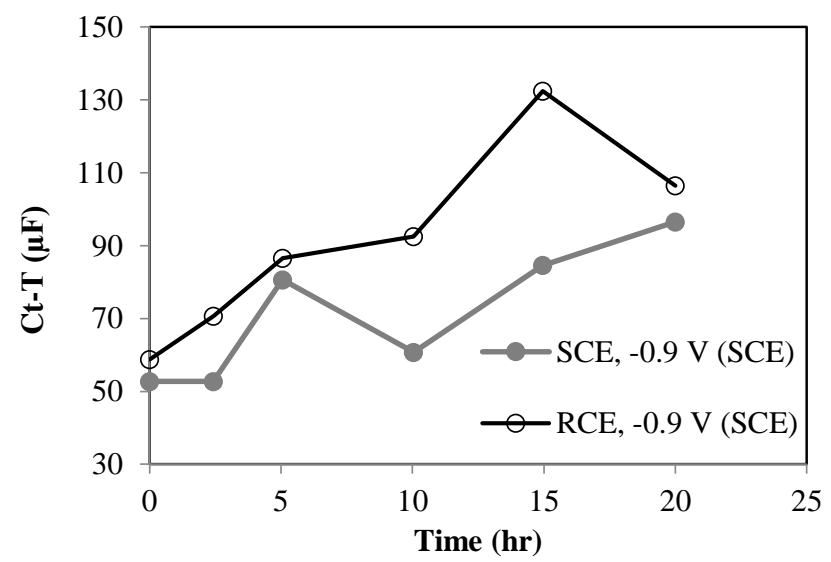

Figure 6. Ct- time diagram for Al5083 polarized in different conditions in $\mathrm{NaCl}$ solution

As mentioned earlier, $\mathrm{Rp}$ is the surface resistance of the passive layer and its variation with time indicates the variations of passive layer's surface resistance to corrosion. Since F (the pitted surface fraction) is very small, $\mathrm{Rp}$ and $\mathrm{Rp} /(1-\mathrm{F})$ can be considered equal. There $\mathrm{Rp} /(1-\mathrm{F})$ value can be used in plots of passive layer's surface resistance to corrosion vs. time. On the other hand $\mathrm{Rpit} / \mathrm{F}$ variations denote the variations of pit growth rate on the surface or increase in the pitting area. For instance if $\mathrm{Rp} / \mathrm{F}$ decreases with time, it can be said that pit growth rate on the surface and/or the pitting area is increased $[10,13]$. Figure 7 and 8 illustrate diagrams of $\mathrm{Rp}$ and Rpit/F as a function of time for RCE and SCE at $-0.9 \mathrm{~V}$ SCE.

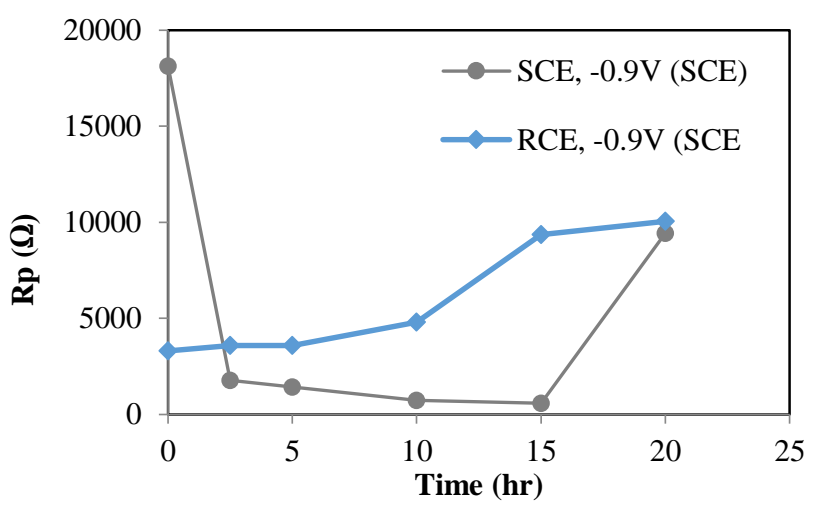

Figure 7. Rp variations with time for static Al5083 samples polarized in $-0.9 \mathrm{~V}$ at $\mathrm{NaCl}$ solution.

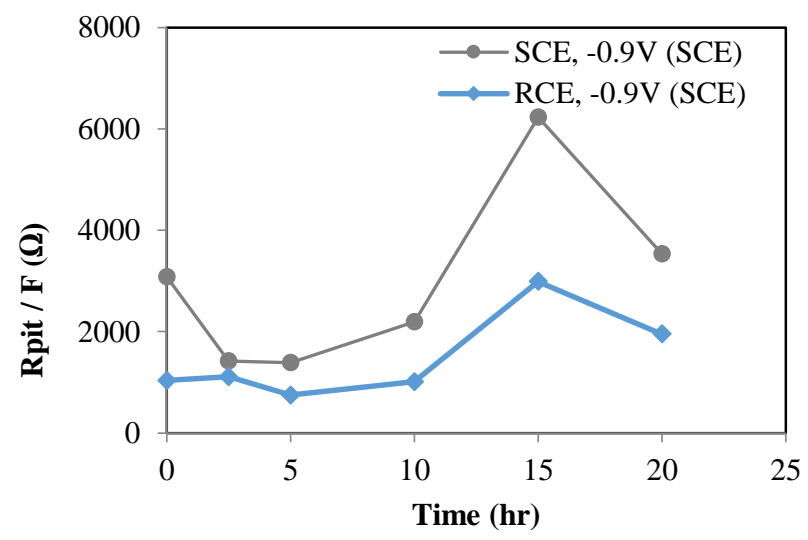

Figure 8. $\mathbf{R}_{\text {pit/F variations with time for static } \mathbf{A l 5 0 8 3} \text { samples }}$ polarized at $-0.9 \mathrm{~V}$ in $\mathrm{NaCl}$ solution.

For the rotating sample polarized at $-0.9 \mathrm{~V}, \mathrm{R}_{\mathrm{pit}} / \mathrm{F}$ increases with time, although $\mathrm{C}_{\mathrm{t}}$ decreases with time. This indicates that even though the pits still nucleate their growth rate on the surface decreases and as a result the improved surface resistance to corrosion $\left(\mathrm{R}_{\mathrm{p}}\right)$.

\subsection{Analysis of variation of $R p$ and Rpit/F with time for steady and rotating samples}

For RCE and SCE samples polarized at $-0.9 \mathrm{~V}$, changing the flow dynamics from static to dynamic results in an increase in growth rate of the pits on the surface and the pitted surface fraction (Rpit/F diagrams in figure 8), however the corrosion resistance of the passive layer is a function of time ( $R p$ diagrams in figure 7). At the beginning of the experiment, $\mathrm{Rp}$ of SCE sample is much larger than that of RCE sample (18170 Ohms and 3357 Ohms respectively). During the 
experiment, the polarization resistance of SCE sample decreases rapidly while the polarization resistance of the rotating sample increases. This trend continues for 20 hours after which the polarization resistance of SCE starts to increase and reaches that of RCE sample.

\subsection{Estimation of the relation between pits growth rate on the surface and time}

The relationship between pits growth rate on the surface and time is an interesting subject in pitting corrosion studies. Mansfeld in his research proposed that the relation between pits growth rate on the surface and time can be estimated by calculating the pitted surface fraction $(\mathrm{F})$ after completion of the experiment, although this relation could be sheer approximation (Florian Mansfeld, 1990).

In this method, at the beginning of the experiment, $\mathrm{t}=0$ and $\mathrm{F}=0$, and according to the following equation:

$$
\mathrm{C}_{\mathrm{t}}=\mathrm{C}_{\mathrm{p}}(1-\mathrm{F})+\mathrm{FC}_{\mathrm{pit}}
$$

And so:

$$
\mathrm{C}_{\mathrm{t}}=\mathrm{C}_{\mathrm{p}}
$$

In this method $C_{p}$ variations during the experiment are assumed to be negligible and considered constant, Therefore the estimated values of $F$ during the experiment can be determined by time dependence of $\mathrm{Ct}$. If $\mathrm{F}$ is determined by microscopic observation after the experiment, a constant parameter $\left(\mathrm{C}^{0}{ }_{\text {pit }}\right)$ can be defined as follow:

$$
\mathrm{C}_{\mathrm{pit}}^{0}=\mathrm{C}_{\mathrm{p}, \exp } / \mathrm{A}_{\mathrm{pit}}
$$

where $A_{p i t}$ is the pitted area and $C_{\text {pitexp }}$ is an experimental parameter that assuming $\mathrm{F}$ to be very small,can be calculated as follow:

$$
\mathrm{C}_{\mathrm{pi} \text { expt }}=\mathrm{FC}_{\mathrm{pit}}=\mathrm{C}_{\mathrm{t}}-\mathrm{C}_{\mathrm{p}}
$$

Assuming pits to be spherical and $A_{t}$ as the total area of the test:

$$
\mathrm{A}_{\mathrm{pi}},=2 \mathrm{FA}_{\mathrm{t}}
$$

Using the above equations, F can be calculated for different times during the experiment. The calculated values can be applied for determination of specific polarization resistance of pitted regions (R0pit) because:

$$
\mathrm{R}_{\text {pit }}^{0}=\mathrm{R}_{\text {pit,exp }} \mathrm{A}_{\text {pit }}
$$

Rpit,exp is the conformity parameter which is equal to:

$$
\mathrm{R}_{\text {pit,exp }}=\mathrm{R}_{\text {pit }} / \mathrm{F}
$$

The values of $\mathrm{R}_{\text {pit }}^{0}$ in different times of the experiments are used to estimate the relation of pits propagation rate $\&$ surface growth and time.

After the calculation of $\mathrm{R}_{\mathrm{pit}}^{0}, \log \left(1 / \mathrm{R}_{\mathrm{pit}}^{0}\right)-\log (\mathrm{t})$ diagram is graphed, and is defined by a straight line. The line equation shows the relation between 1/R0pit and time i.e. the relation between the pits growth rate and time. The general form of the equation is as follow(Florian Mansfeld, 1990):

$$
\log \left(\frac{1}{R_{p i t}^{0}}\right)=\log a+b \log (t)
$$

And the exponential form is:

$$
\frac{1}{R_{p i t}^{0}}=a(t)^{b}
$$

The relation between the pits growth and time for RCE sample polarized at $-0.9 \mathrm{~V}$ is estimated as follow.

For this sample, at $\mathrm{t}=0, \mathrm{Ct}=60.984 \mu \mathrm{F}$ (the numerical values of the equivalent circuit elements for all samples and for different times are given in Tables 4). If at this time $\mathrm{F}$ value is considered zero (which is near the truth), $\mathrm{Cp}$ value will be $60.984 \mu \mathrm{F}$. The final $\mathrm{F}$ value after the test completion is given in Table 2, $\mathrm{F}$ for this sample is 0.032 or $3.2 \%$. final area of the pits can be determined by below equation:

$$
\begin{aligned}
& \mathrm{A}_{\text {pit }) \text { final }}=2 \mathrm{~F}_{\text {) final }} \mathrm{A}_{\mathrm{t}}=2 * 0.032 * 8.81 \\
& =0.56 \mathrm{~cm}^{2}
\end{aligned}
$$

where, $A_{\text {pit }}$ is the area of the pitted surface assuming the pits to be spherical and $A_{t}$ is the total area under experiment.

$\mathrm{C}_{\text {pitexp }}$ is an experimental parameter and its value after the experiment completion is calculated as follow, if $\mathrm{F}$ is considered very low:

$$
\begin{gathered}
\mathrm{C}_{\text {pitexp)final }}=\mathrm{FC}_{\text {pit) final }}=\mathrm{C}_{\mathrm{t} \text { )final }}-\mathrm{C}_{\mathrm{p}}= \\
106.18-60.984=45.196 \mu \mathrm{F}
\end{gathered}
$$

Now the constant parameter for this sample can be calculated:

$$
\begin{aligned}
& \mathrm{C}_{\text {pit }}^{0}=\mathrm{C}_{\text {pitexp)final }} / \mathrm{A}_{\text {pit)final }}=\frac{45.1196}{0.56}=80 \mu \mathrm{Fcm}^{-2} \\
& =0.000080 \mathrm{Fcm}^{-2}
\end{aligned}
$$

And the estimated value of $F$ in $t((F) t)$ and $\left(\mathrm{R}^{0}{ }_{\text {pit)t }}\right.$ can be calculated:

$$
\begin{aligned}
& \text { Step 1: } C_{\text {pit,exp)t }}=F_{\text {pittt }}=C_{t) t}-C_{p} \\
& \text { Step 2: } \mathrm{C}_{\text {pit }}^{0}=\mathrm{C}_{\text {pit,exp)t }} / \mathrm{A}_{\text {pit)t }} \stackrel{C_{\text {pit }}^{0} \text { cte }}{\longrightarrow} \mathrm{A}_{\text {pit })}=\frac{\left.C_{\text {pit,exp }}\right)_{t}}{C_{\text {pit }}^{0}} \\
& \text { Step 3: } \mathrm{A}_{\text {pit)t }}=2 \mathrm{~F}_{) \mathrm{t}} \mathrm{A}_{\mathrm{t}} \rightarrow \mathrm{F}_{\mathrm{t} t}=\frac{\left.A_{\text {pit }}\right)_{t}}{2 A_{t}} \\
& \text { Step 4: } \mathrm{R}_{\text {pit)t }}^{0}=\mathrm{R}_{\text {pit,exp)t }} * \mathrm{~A}_{\text {pit)t }}
\end{aligned}
$$

For example, $F$ value after 2.5 hours $\left(\left(\mathrm{F}_{2.5}\right)\right.$ and $\mathrm{R}_{\mathrm{pit}}^{0}$ at this time is:

$$
\begin{aligned}
& \text { Step 1: } \mathrm{C}_{\text {pitexp)2.5 }}=\mathrm{FC}_{\text {pit)2.5 }} \\
& =67.105-60.984=6.121 \mu \mathrm{F} \\
& \text { Step 2: } \mathrm{A}_{\text {pit)2.5 }}=\frac{6.121}{80}=0.08 \mathrm{~cm}^{2} \\
& \text { Step 3: } \mathrm{F}_{\text {)2.5 }}=\frac{\left.A_{\text {pit }}\right)_{2.5}}{2 A_{t}}=0.004 \\
& \text { Step 4: } \mathrm{R}_{\text {pit)2.5 }}^{0}=\mathrm{R}_{\text {pitexp)2.5 }} * \mathrm{~A}_{\text {pit)2.5 }} \\
& =1083 * 0.08=86.64 \Omega \mathrm{cm}^{2}
\end{aligned}
$$

Same calculations can be used for different times and different samples, and by calculating the R0pit value, 
the $\log \left(1 / \mathrm{R}^{0}{ }_{\text {pit }}\right)-\log (\mathrm{t})$ diagram can be drawn and the passing line equation can be determined.

Figure 9 show $\log \left(1 / \mathrm{R}_{\mathrm{pit}}^{0}\right)$ diagrams as a function of $\log (\mathrm{t})$ for SCE and RCE samples and the estimated line equation.

These equations are shown in exponential form in Table 5. The equations in Table 4 show that the pits growth rate decreases with time i.e. as pits grow bigger, their growth rate decreases.

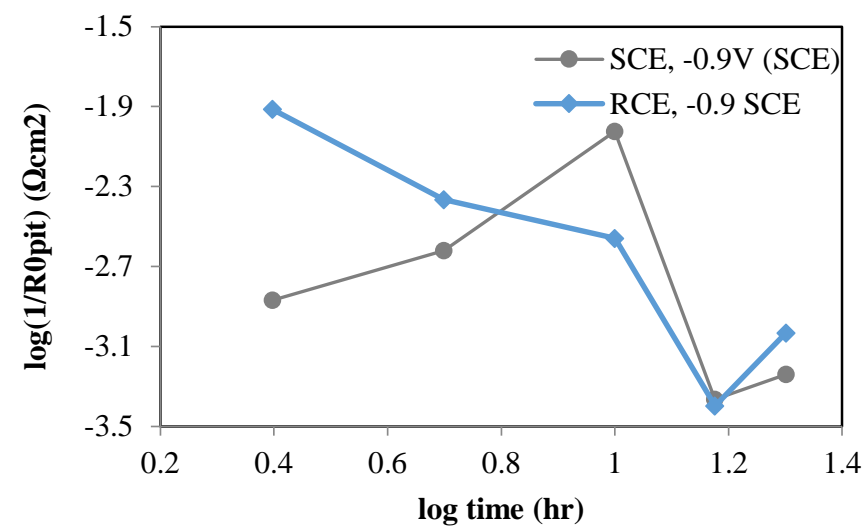

Figure 9. $\log (1 /$ R0pit) diagrams as a function of $\log (t)$ and the passing lines (dotted lines) for SCE and RCE Al 5083 samples resulting from cathodic polarization at $\mathbf{- 0 . 9} \mathrm{V}$ for $20 \mathrm{hours}$ in NaCl solution.

Table 5. The passing line of $\log$ (1/ R0pit) diagrams as a function of $\log (t)$ in exponential form for SCE $\mathbf{A l 5 0 8 3}$ samples of resulted from cathodic polarization in - 0.9 VSCE for 20 hours in NaCl solution.

\begin{tabular}{cc}
\hline Sample & Passing Line Equation \\
\hline SCE sample & $\frac{1}{R^{0}{ }_{p i t}}=10^{-1.33}(t)^{-1.45}$ \\
\hline RCE Sample & $\frac{1}{R_{p i t}^{0}}=10^{-1.36}(t)^{-1.39}$ \\
\hline
\end{tabular}

\section{Conclusion}

Under static condition and cathodic polarization, after $20 \mathrm{hr}$, the overall corrosion resistance of the 5083 alloy's surface decreases and the surface growth rate of the pits decreases as well. Under dynamic flow condition and cathodic polarization, the corrosion resistance of the surface increases with time whereas the surface growth rate of the pits decreases. At $-0.9 \mathrm{~V}$, upon altering the flow condition from static to dynamic, the surface growth rate of the pits and their surface fraction increases while the corrosion resistance of the passive layer is time dependent.

\section{References}

1- Davis, J. A. (1999). Corrosion of Aluminum and Aluminum Alloys. ASM International, Materials Park, OH. ISBN: 978-0-87170-629-4

2- Davis, J. A., \& Gehring, G. A. (1975). The Effect of Velocity on the seawater Corrosion Behaviour of High Performance Ship Materials. Materials Performance, 14, 32-39.
http://doi.org/10.1007/SpringerReference_9592. 3- F. J. Martin, G. T. Cheek, W. E. O. and P. M. N. (2005). Impedance Studies of the Passive Film on Aluminum. Corrosion Science, 47, 3187-3201.

4- Gehring, G., \& Peterson, M. (1981). Corrosion of 5456-H117 Aluminium in High Velocity Seawater. Corrosion Journal, 37, 232-242.

5- Gunderson, R., \& Nisancioglu, K. (1990). Cathodic Protection of Aluminium in Seawater. Corrosion Journal, 46(4), 279-285.

6- Holtan, K. N. and H. (1979). Cathodic Polarization $f$ Commercially Pure Aluminum. Corrosion Science, $19,534-552$.

7- Kim, S.-J., Jang, S.-K., Han, M.-S., Park, J.-C., Jeong, J.-Y., \& Chong, S.-O. (2013). Mechanical and elec-trochemical characteristics in sea water of 5052$O$ aluminum alloy for ship. Transactions of Nonferrous Metals Society of China, 23(3), 636-641. http://doi.org/10.1016/S1003-6326(13)62510-8.

8- Kim, S.-J., Kim, S.-K., \& Park, J.-C. (2010). The corrosion and mechanical properties of Al alloy 5083H116 in metal inert gas welding based on slow strain rate test. Surface and Coatings Technology, 205, S73S78. http://doi.org/10.1016/j.surfcoat.2010.04.039.

9- Mansfeld, F. (1990). Electrochemical impedance spectroscopy (EIS) as a new tool for investigating methods of corrosion protection. Electrochimica Acta, 35(10), 1533-1544.

http://doi.org/10.1016/0013-4686(90)80007-B.

10- Mansfeld, F., Lin, S., Kim, S., \& Shih, H. (1987). Pitting andSurface Modification of SiC/Al. Corrosion Science, 27, 997-1001.

11- Mansfeld, F., Lin, S., Kim, S., \& Shih, H. (1989). Corrosion Protection of Al Alloys and Al-Based Metal Matrix Composites by Chemical Passivation. Corrosion Journal, 45, 615-630.

12- Meng, C., Zhang, D., Cui, H., Zhuang, L., \& Zhang, J. (2014). Mechanical properties, intergranular corrosion behavior and microstructure of $\mathrm{Zn}$ modified Al-Mg alloys. Journal of Alloys and Com-pounds, 617(0), 925-932.

http://doi.org/10.1016/j.jallcom.2014.08.099.

13- Ornek, D., Jayaraman, A., Wood, T. K., San, Z., Hsu, C. H., \& Mansfeld, F. (2001). Pitting Corrosion Control Using Regenerative Biofilms on Aluminium 2024 in Artifical Seawater. Corrosion Science, 43, 2121-2133.

14- Park, D.-H., Choi, S.-W., Kim, J.-H., \& Lee, J.-M. (2015). Cryogenic mechanical behavior of 5000- and 6000-series aluminum alloys: Issues on application to offshore plants. Cryogenics, 68, 44-58.

http://doi.org/10.1016/j.cryogenics.2015.02.001 15- Szklarska-Smialowska. (2012). Pitting Corrosion of Aluminum. Corrosion Science, 41, 1743-1764. 